\title{
Trousseau Syndrome Secondary to Carcinoma Gall Bladder: Case Report
}

\author{
Parul Bhardwaj ${ }^{1}$, Shivbrat Sharma ${ }^{2}$ \\ ${ }^{1}$ MD Internal Medicine, Civil Hospital Dehra (H.P.) \\ ${ }^{2}$ Junior Resident ENT, DRPGMC Kangra at Tanda (H.P.) \\ Corresponding Author: Shivbrat Sharma
}

\begin{abstract}
Trousseau syndrome is the phenomenon in which an occult visceral malignancy is the underlying cause of an unexpected thrombotic event. Trousseau syndrome has a wellestablished association with advanced primary pancreatic and pulmonary malignancies and others like prostate, stomach, colon, and hematologic malignancies can be associated. Here we report a case from whose initial presentation we thought that it was stroke, but later she developed DVT in both legs and after investigation it was suspicious of carcinoma gall bladder.
\end{abstract}

Keywords: DVT- deep vein thrombosis, VTEvenous thromboembolism, trousseau syndrome

\section{INTRODUCTION}

In 1865, Armand Trousseau defined trousseau syndrome as the phenomenon in which an occult visceral malignancy is the underlying cause of an unexpected thrombotic event. Initially, the most frequent description involved migratory thrombophlebitis [1-3]. After sometime; it also included chronic disseminated intravascular coagulopathy, micro angioplasty, verrucous endocarditis, and arterial emboli. Trousseau syndrome has a well-established association with advanced primary pancreatic and pulmonary malignancies, approximately $20 \%$ and $24 \%$ respectively [4-6]. Others like prostate, stomach, colon, and hematologic malignancies can be associated.
Here we report a case from whose initial presentation we thought that it was stroke, but later she developed DVT in both legs and after investigation it was suspicious of carcinoma gall bladder. She was then referred to higher centre for further evaluation.

\section{CASE REPORT}

45year female not known case of diabetes mellitus and hypertension presented with gradual progressive painless bilateral loss of vision for last one week and fever for last 4 days in medicine OPD and the patient was admitted for evaluation. Fever was undocumented, not associated with chills and rigors, no evening rise of temperature. There was no history of weakness in any limbs, headache, altered sensorium, pain abdomen, altered bowel habits, loss of appetite and loss of weight. On general physical examination pallor was present on palpable conjunctiva. On eye examination visual acuity of both eyes was finger counting at 1 feet, pupil bilateral reacted normally, IOP of both eyes was normal, cornea was clear and fundus was within normal limit. On per abdomen liver was palpable $2 \mathrm{~cm}$ below right coastal margin and rest of systemic examination was normal. Blood investigations were send. On investigations Hb-9.7, TLC-14 thousand, platelet count-two lakh eighty thousand, ESR-130mm, peripheral smearnormocytic normochromic anaemia, total bilirubin-0.2mg/dl, SGOT-176 IU, SGPT127 IU, creatinine- $1.18 \mathrm{mg} / \mathrm{dl}$ and urine 
microscopy examination was normal. HBsAg, Anti HCV and ICTC were non reactive. Urine culture and blood culture was sterile. Chest X-ray was normal. NCCT was done which show multiple infarcts in bilateral parieto-occipital region. After two days of admission patient complained of pain and swelling in left lower leg and also complained about pain right upper abdomen. USG Doppler was done which show left SFV, SFJ, popliteal vein shows echogenic lumen with non compressibility of vessel suggestive of DVT. On USG abdomen showed liver enlarged in size with multiple well defined rounded hypoechoic lesion in liver parenchyma giving

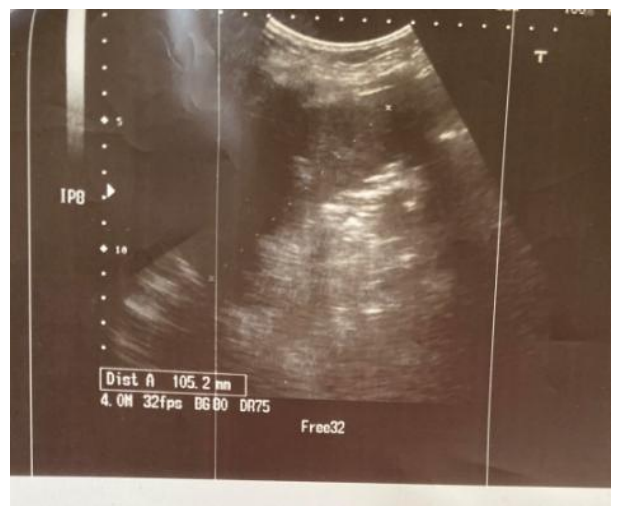

a)

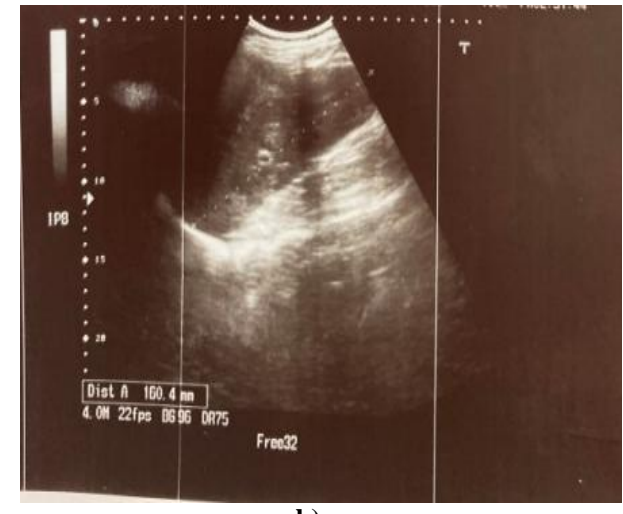

b)

Fig.: a) and b) showing USG abdomen showing cholelithiasis and multiple hypoechoic lesion in liver

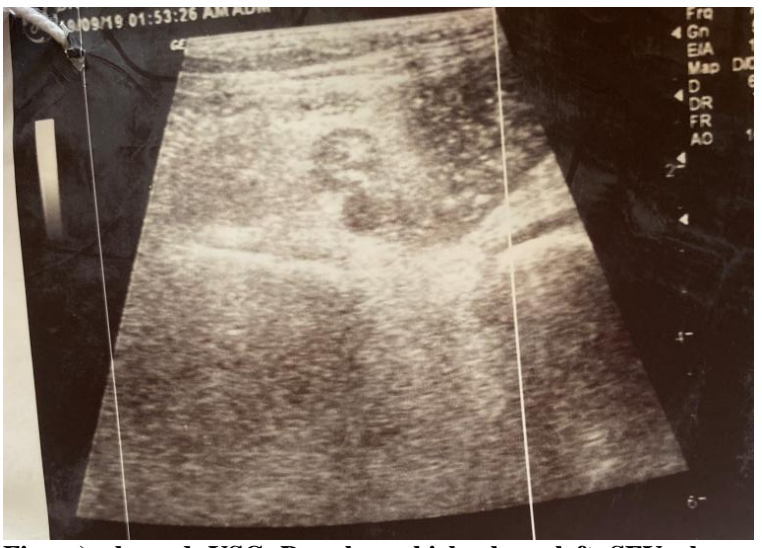

Fig: c) showed USG Doppler which show left SFV shows echogenic lumen.

\section{DISCUSSION}

Gallbladder carcinoma is relatively rare, and the incidence in the United States has been reported to range from 1.2-2.5 cases per 100,000 [7,8]. It most often develops in the sixth or seventh decade of life, and affects females three to four times appearance of target lesion suggestive of metastasis and gall bladder shows multiple calculi. Patient was worked for malignancy and started on enoxaparin and warfarin for DVT. Then patient was planned for CECT abdomen and it showed an exophytic mass arising from medial wall of gall bladder with local peri-portal and aortic lymph node enlargement was noted-suspicion of carcinoma gall bladder. The patient was referred for higher centre for further evaluation and treatment. Patient was diagnosed with carcinoma gall bladder at higher centre which was confirmed by the records on follow up. more often than males. The etiology of gallbladder carcinoma is not known exactally. Cholelithiasis has been reported to occur in $75 \%$ to $92 \%$ of cases [7]. Other factors linked to gallbladder carcinoma include: cholecystoenteric fistulas, anomalous pancreaticobiliary junction, exposure to chemical carcinogens, inflammatory bowel disease, familial predisposition, chronic salmonella, and Mirizzi syndrome. Patients most commonly present with nausea, vomiting, weight loss, loss of appetite, pain abdomen and jaundice. On palpation, right upper quadrant tenderness can be present.

Cancer is a prothrombotic state which can lead to vascular complications, especially DVT and pulmonary embolism and venous thromboembolism [9]. Arterial 
thrombosis can also occur, including stroke and myocardial infarction [10].

The prothrombotic state in cancer involves procoagulant molecules produced by tumor cells, suppression of fibrinolytic activity and platelet activation [10]. Tissue factor (TF) expressed by tumor cells is most important procoagulant which present on neoplastic cells as well as on tumorassociated endothelial cells [11]. TF contributes to tumor growth, metastasis and angiogenesis by a variety of mechanisms [12]. Its expression is associated with increased angiogenesis, tumor invasiveness and worsened prognosis in various malignancies [13]. TF containing microvesicles secreted into the circulation results the systemic coagulopathy of cancer [10].

Anticoagulants are the mainstay of treatment of DVT caused by malignancy. Initial therapy LMWH and UFH are equally effective in reducing recurrent thrombosis in patients with cancer, but LMWH is associated with a 3 month survival benefit over UFH and also with a lower risk of heparin-induced thrombocytopenia [14].

Declaration of Patient Consent: The authors certify that we have obtained all appropriate patient consent on forms regarding clinical information to be reported in the journal.

\section{Financial Support and Sponsorship: Nil.}

Conflict of Interest: There are no conflicts of interest.

\section{Acknowledgement: None}

\section{Source of Funding: None}

\section{REFERENCES}

1. Van Doormaal FF, Atalay S, Brouwer HJ, van der Velde EF, Buller HR, van Weert HC. Idiopathic superficial thrombophlebitis and the incidence of cancer in primary care patients. Ann Fam Med. 2010; 8: 47-50.

2. Kawaguchi S, Ishiguro A, Suzuki K, Hanada N, Takahata T, Itoh J, et al. A case of unrespectable advanced gastric cancer with Trousseau syndrome. Gan to Kagaku Ryoho. 2009; 36: 317-320.

3. Varki A. Trousseau's syndrome: multiple definitions and multiple mechanisms. Blood. 2007; 110: 1723-1729.

4. 5. Mazer LM, Losada HF, Chaudhry RM, Velazquez-Ramirez GA, Donohue JH, Kooby DA, et al. Tumor characteristics and survival analysis of incidental versus suspected gallbladder carcinoma. Department of Surgery, Emory University, 1364 Clifton Road, NE, Suite H-124-C, Atlanta, GA, 30322, USA. J Gastrointest Surg. 2012; 16:1311-1317.

5. NCCN Clinical Practice Guidelines in Oncology-Hepatobiliary Cancers.

6. Donati MB, Lorenzet R. Thrombosis and cancer: 40 years of research. Division of Immunohematology and Transfusion Medicine, Ospedali Riuniti di Bergamo, Bergamo, Italy. Thromb Res. 2012; 129: 348-352.

7. The Anderson M Surgical Oncology Handbook, 4th edition. By Barry W Feig, MD, David H. Berger, M.D., George M. Fuhrman, M.D. 356-358.

8. Grobmyer SR, Lieberman MD, Daly JM. Gallbladder cancer in the twentieth century: single institution's experience. World J Surg. 2004; 28: 47-49.

9. Hutten BA, Prins MH, Gent M, Ginsberg J, Tijssen JG, Büller HR. Incidence of recurrent thromboembolic and bleeding complications among patients with venous thromboembolism in relation to both malignancy and achieved international normalized ratio: a retrospective analysis. $\mathbf{J}$ Clin Oncol. 2000;18(17):3078-83.

10. Lee AYY, Khorana AA. Cancer Associated Thrombosis. In: DeVita VT, Lawrence TS, Rosenberg SA eds. DeVita, Hellman and Rosenberg's Cancer Principles and Practice of Oncology. 10th ed. Philadelphia: Wolters Kluwer; 2015: 1969-75.

11. Yu JL, May L, Lhotak V, Shahrzad S, Shirasawa S, Weitz JI, et al. Oncogenic events regulate tissue factor expression in colorectal cancer cells: implications for tumor progression and angiogenesis. Blood. 2005;105(4):1734-41.

12. Kasthuri RS, Taubman MB, Mackman N. Role of tissue factor in cancer. J Clin Oncol. 2009;27(29):4834-8.

13. Belting M, Ahamed J, Ruf W. Signaling of the tissue factor coagulation pathway in 
angiogenesis and cancer. Arterioscler Thromb Vasc Biol. 2005;25(8):1545-50.

14. Akl EA, Rohilla S, Barba M, Sperati F, Terrenato I, Muti P, et al. Anticoagulation for the initial treatment of venous thromboembolism in patients with cancer: a systematic review. Cancer. 2008;113(7): 1685-94.
How to cite this article: Bhardwaj P, Sharma S. Trousseau syndrome secondary to carcinoma gall bladder: case report. International Journal of Science \& Healthcare Research. 2021; 6(3): 116-119. DOI: https://doi.org/10.52403/ijshr. 20210719 